\title{
The relative influence of change in habitat and climate on elevation range limits in small mammals in Yosemite National Park, California, U.S.A.
}

\author{
Maria J. Santos ${ }^{1 *}$ D, Adam B. Smith², James H. Thorne ${ }^{3}$ and Craig Moritz ${ }^{4}$
}

\begin{abstract}
Background: Different processes determine species' geographic ranges, including species' responses to changing climate, habitat, or both simultaneously. Here we ask which combination of factors best predicts shifts in the upper and lower elevation range limits and overall range of small mammal species in Yosemite National Park, California, USA across the last 100 years.

Methods: We used species distribution models (SDMs) to predict elevation range dynamics of small mammals between 1910 and 1930 and 2003 and 2010, based on combinations of habitat and climate variables, and compared the predicted SDM distribution with the "observed" range from occupancy modelling (OM).

Results: SDM model convergence was successful for eight species. Predictions of elevation range shifts from the SDMs agreed with OM for four of these species; while the other four could be partially predicted. SDMs predicted shifts in lower limits (six correct) better than upper limits (five correct). The five correctly predicted upper limit shifts were best predicted with climate; whereas five out of the six lower elevation shifts included habitat. SDMs were best at predicting range contraction at higher elevations.

Conclusions: Climate generally had a stronger effect on range dynamics than habitat, especially at higher elevations. However, at mid-elevations SDMs showed an increasing importance of habitat on range shifts at these elevations, in the cases range shifts were reliably predicted. Predicting elevation range shifts on the basis of climate or habitat alone is insufficient, as habitat and climate play varying roles at different elevations, associated with different processes underlying range shifts. Failure to predict observed range shifts may arise from biotic interactions, behaviour flexibility, or evolutionary adaptation, aspects which are only beginning to be incorporated into distribution modelling frameworks.
\end{abstract}

Keywords: Small mammals, Occupancy modelling, Range shifts, Species distribution models, Maxent, Climate, Habitat

\section{Background}

Montane species are especially vulnerable to rapid changes in climate [1,2], which adds urgency to understanding their elevation range dynamics. Generally it has been expected that climate change will drive species upwards in elevation [3-6], challenging their ability to persist [1]. However, recent research suggests that the picture is more complex, as

\footnotetext{
* Correspondence: M.J.FerreiraDosSantos@uu.nl

'Department of Innovation, Environmental and Energy Sciences, Utrecht University, Utrecht, Netherlands

Full list of author information is available at the end of the article
}

different factors - temperature, precipitation and habitat may force range shifts in multiple directions [7-11] and affect upper and lower range limits differently [12], with and the relative contribution of different factors varying by elevation [13]. Therefore, it is important to investigate the relative forcing of factors across historical data to better anticipate future responses to climate change which may result in species redistributions [14], community disassembly [15], and novel ecosystems [16].

Changes in temperature and precipitation affect habitat, which in turn may be tracked by animals and result 
in range shifts [13, 17]. Changes in temperature and precipitation affect plant distribution [18], physiology and phenology $[19,20]$, influencing plant productivity and the production of food resources that fauna may depend on. These vegetation-mediated climate effects may show a lag, a slow down or neutralization of the animals' responses to direct climate effects as animals may stay present as long as the habitat provided by vegetation does [1].

Animal species respond to changes in temperature and precipitation through a variety of mechanisms, such as physiological adaption [21, 22], behavioural change [23], and evolutionary alteration of their environmental niche $[24,25]$. The effect of temperature is especially pronounced on mammals at higher elevations [26], where changes in radiation or minimum temperature can affect thermoregulatory capacity, return from hibernation [27], ability to survive [14], behaviour, and foodweb structure [28]. Effects of changing precipitation on mammals are less direct $[4,26]$ but include challenges in finding water (for drinking or maintenance of their preferred habitats) or cover (e.g., below the snow pack). Changes in moisture can also affect metabolic costs arising from getting wet (i.e., from rainfall) [29] and from difficulties in thermoregulation through transpiration when relative humidity is high $[22,26]$.

Here we assess the relative influences of habitat and climate on species range dynamics. Small mammals likely respond to different factors across their elevation range. For example, Santos et al. [13] showed how habitat was associated with species range shifts in low to mid-elevation ranges, while Rubidge et al. [30] demonstrated the cumulative effects of climate and habitat on a high elevation mammal species. Finally, Morelli et al. [31] showed that anthropogenic amelioration of habitat at a species lower range limit can reduce impacts of climate change.

We examine whether the recorded elevation range shifts of eight small mammals inhabiting a variety of elevation ranges across Yosemite National Park, California, USA [5], are matched by predictions from species distribution models (SDMs). We compared predictions from SDMs trained with climate or habitat or with a combination of the two, with observed shifts in elevation ranges inferred from occupancy modelling, to see which set of predictors most reliably predicted the observed shifts in range. In previous work, Moritz et al. [5] found that, over $\sim 100$ years, these same high elevation species contracted their ranges upwards, while mid-elevation species expanded their ranges downwards, and suggested that these shifts are consistent with a warming climate across the study area. Yosemite National Park experienced an increase in temperature and decrease in precipitation over the last 100 years [13], which also resulted in downwards vegetation shifts aligned with increasing precipitation levels. The early establishment date of the Park prevented much logging and other land use that has occurred more widely in the Sierra Nevada Mountains [32], while fire was present throughout the century. We expected climatebased models to be better than habitat-based models at predicting range shifts of high elevation species because species may respond strongly to exposure to temperature and radiation because they may be closer to their thermal physiological limits [30]. For the same reason we expected climate-based models to be better at predicting upper range limits than lower range limits, except in cases where the upper limit is already at the maximum possible elevation. In contrast, we expected habitat, or habitat plus climate, to be better predictors of low-elevation dynamics because these include both direct and indirect effects on species range shifts: direct by responses to increase in temperature, radiation and changes in precipitation; and indirect by tracking habitat shifts.

\section{Methods \\ Study area}

The study area covers $3350 \mathrm{~km}^{2}$, including Yosemite National Park, California, USA, and encompasses an elevation transect from 100 to $3500 \mathrm{~m}$ on the western slope of the Sierra Nevada (Fig. 1). Different plant communities dominate at different elevations, with oak woodlands and chaparral at the lower elevations $(<1500 \mathrm{~m})$; hardwoods, Ponderosa pine (Pinus ponder$o s a)$ and other pine species at intermediate elevations (1000-2500 m); lodgepole pine (Pinus contorta); fir and hemlock at higher elevations (2000-3200 m); and alpine conditions above the tree line. This transect covers the entire elevation range from the valley bottom to the high elevations of Yosemite National Park, and thus covers the full elevation range that the mammal species could occupy.

\section{Climate data}

We selected 4 climate predictors: minimum temperature, maximum temperature, mean annual precipitation, and climatic water deficit (CWD, potential evapotranspiration minus actual evapotranspiration; Additional file 1: S2 and Additional file 1: Table S2.1). We used downscaled climate variables at a spatial resolution of $270 \mathrm{~m}$ using the Basin Characterization Model (Additional file 1: S1) [33, 34]. The downscaled historical climate data were derived from the PRISM data set (http://www.prism.oregonstate.edu/) [35], which provides minimum temperature, maximum temperature, and precipitation on a monthly and yearly time steps [36]. The monthly and yearly weather products were converted into 30-year averages (1911-1940 and 1971-2000), which reduces the potential bias from 


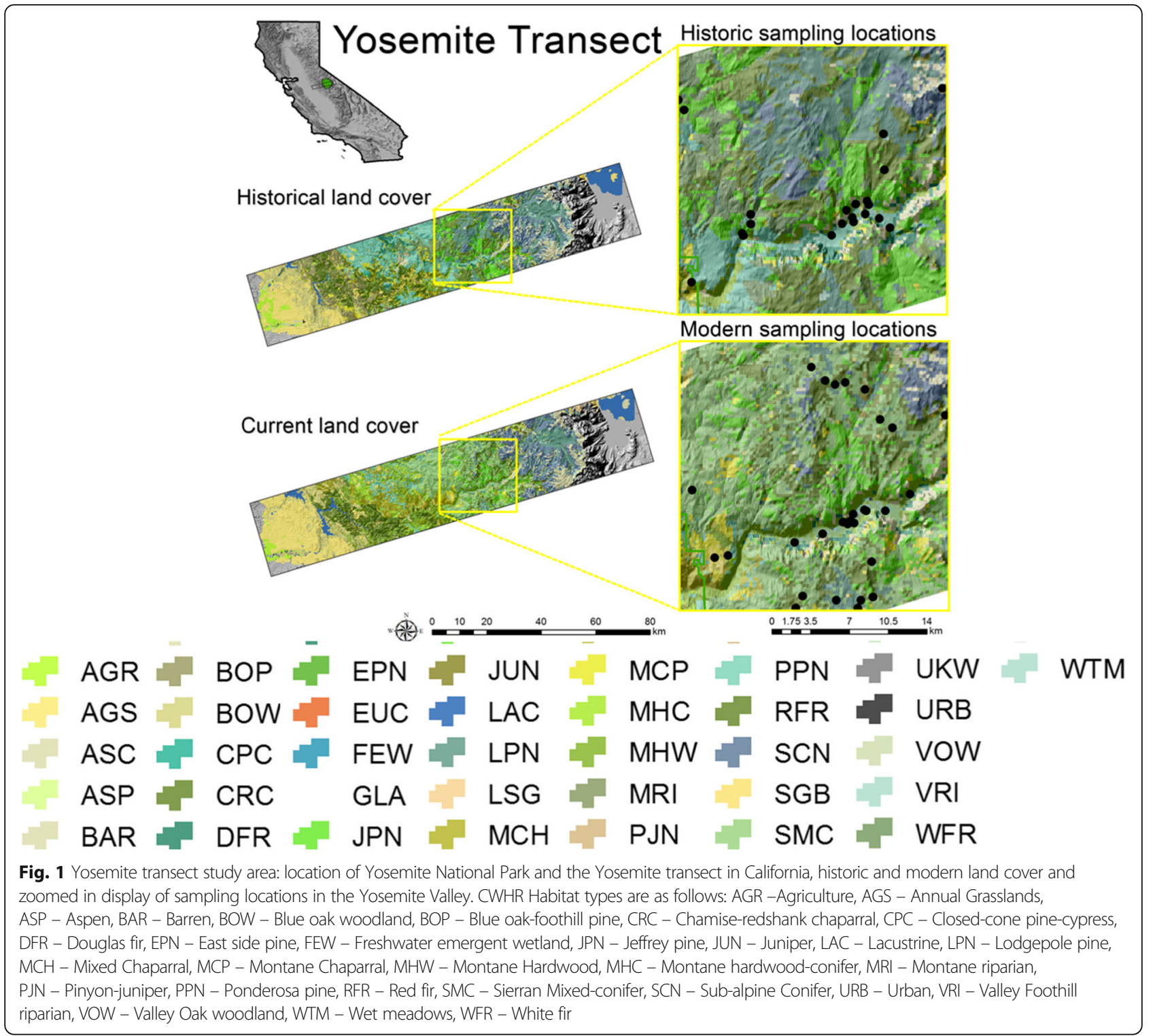

weather cycles (for example, the Pacific Decadal Oscillation) and extreme weather events.

\section{Habitat data}

We used digital historic (1934) and contemporary (2000) vegetation types maps (Additional file 1: S1). The Wieslander data set corresponds to 1930s vegetation surveys. Surveyors mapped vegetation communities throughout the state. Surveyors color-coded topographic maps to reflect the vegetation communities they observed, and annotated the maps with the spatially dominant plant species in each polygon. These maps were georeferenced and hand-digitized on-screen to produce a spatial digital layer of land cover in the 1930s $[37,38]$. Given the uncertainty of these assessments from vantage points, this dataset was analyzed at a spatial resolution of $300 \mathrm{~m}$.

The contemporary vegetation map is a combination of the best available land cover maps for our study area and time frame: a US National Park Service vegetation map, and a US Forest Service land cover map for the surrounding areas, CalVeg 2000 (https://www.fs.usda.gov/detail/r5/ landmanagement/gis/?cid=STELPRDB5327836). The Park Service map is based off of 1-m digital imagery with handdelineated polygons and a sub-hectare minimum mapping unit while the Forest Service map is based off Landsat imagery, with an original spatial resolution of $30 \mathrm{~m}$. These two maps were combined into a single map by the US Forest Service, and the resulting polygons can be portrayed according to several land cover classifications, including the one used for this study. We rescaled the 
contemporary map to the same $300 \mathrm{~m}$ pixel frame as the historic map, using a majority sample rule.

Land cover types from both periods were crossreferenced to the California Wildlife Habitat Relationships types (hereafter CWHR or habitat; https://www.wildlife.ca.gov/Data/CWHR). The CWHR habitat classification is used by California State agencies to predict the distribution of terrestrial vertebrate species in California. Each habitat is described in terms of its structure, composition, vegetation changes, duration of stages, physical setting (soils, topography, and climate), and geographical distribution in California. In our study area, there are 16 habitat types, namely: agriculture, Blue Oak-Foothill pine, Douglas Fir, Eastside pine, Jeffrey pine, Lodgepole pine, Mixed Chaparral, Montane Chaparral, Montane hardwood-Conifer, Ponderosa Pine, Red Fir, Subalpine conifer, Sierran mixed conifer, white fir and urban (Fig. 1; Additional file 1 S1 includes a description of the dominant species in each habitat type). The cross-reference to the same CWHR habitat type allowed calculation of land cover change between historic and modern habitat, at a spatial resolution of $300 \mathrm{~m}$.

The resolution of the habitat data $(300 \mathrm{~m})$ was close to that of climate data $(270 \mathrm{~m})$ enabling us to link the climate data to the habitat and mammal data. Note that the climate and the habitat data were independently produced, as the climate data was produced from meteorological station data and the habitat data from field surveys. To match climate, habitat and mammal data we established a circle with a $2-\mathrm{km}$ radius around the centroid of the trapping aggregates (see description below). Averages of climate variables and dominant habitat of the cells included within this buffer were used in the subsequent modelling procedure.

\section{Mammal species data}

We selected 8 species out of the 28 in Moritz et al. [5] because these species had an adequate number $(\geq 15)$ of geographically distinct records in each time period [39] for training species distribution models (SDMs). The data represented the full elevation range of each species (Table 1). These included three low elevation species (the Western harvest mouse or Reithrodontomys megalotis, the California ground squirrel or Otospermophilus beecheyi, and the brush mouse or Peromyscus boylii), three high elevation species (the Golden-mantled ground squirrel or Callospermophilus lateralis, the lodgepole chipmunk or Tamias speciosus, and the western jumping mouse or Zapus princeps), plus two species that occur in all elevations, referred to as Low-High (the long-tailed vole or Microtus longicaudus, and the deer mouse or $P$. maniculatus; note that the scientific names have been updated since [5]).

The data used for occupancy modelling consisted of historic and modern capture data with repeated visits (trap nights) at each site within the historic and modern time periods. Capture history data consisted of records of animal capture events per night at each of the trapping stations surveyed by Joseph Grinnell in 1914-1920 and revisited by researchers at University of California Berkeley's Museum of Vertebrate Zoology (MVZ) in 2003-2008. Further details regarding the historic and modern surveys are described in Moritz et al. [5] so we only summarize here. We note that Grinnell's intention was to document the full and complete faunal conditions of California so represent the best available data for that time. Grinnell and his colleagues kept a detailed record of their trapping efforts in field notebooks totalling over $\sim 50,000$ pages, which are housed at the MVZ (http:// ecoreader.berkeley.edu) [40]. Field note books were mined for the information to reconstruct the historical capture histories. Modern capture data were also recorded in field note books and in digital format so they could be retrieved. Historical trapping stations consisted of an average of 24 mouse/rat traps set for an average of 4.6 nights; and in modern times of 40 Sherman live traps were set for 4 consecutive nights. Trapping stations within $2 \mathrm{~km}$ of one another horizontally and $100 \mathrm{~m}$ vertically were aggregated based on their proximity. Joseph Grinnell and colleagues surveyed 54 trapping aggregates, and the Grinnell Resurvey Project re-surveyed the original aggregates and added 47 new aggregates [5].

\section{Analysis}

This study builds on the occupancy models (OM) employed by Moritz et al. [5], and uses those results as "observed" range shifts in the region. Occupancy modelling is a statistical framework that allows simultaneous estimation of a species' probability of detection and probability of occupancy while correcting for differences in survey effort, surveyor bias, and other non-controllable factors [41, 42]. The outputs of this method allow for detection of significant changes in species elevation ranges [5, 9]. Moritz et al. [5] used the probability of detection to determine whether non-detection at a site corresponded to a false absence (the species was always assumed present when detected). True absences were defined as those locations with probability of false absence lower than 0.05. By evaluating this probability across the elevation profile, it was possible to determine which species had significantly contracted, expanded or showed no shifts in their ranges (Table 1; [5]). Range shifts were considered significant if a species expanded and/or contracted the extent covered along the elevation profile (i.e., upper minus lower range limit elevation) by $>10 \%$. We classified species elevation range shifts into those that significantly contracted/expanded and those that did not. 


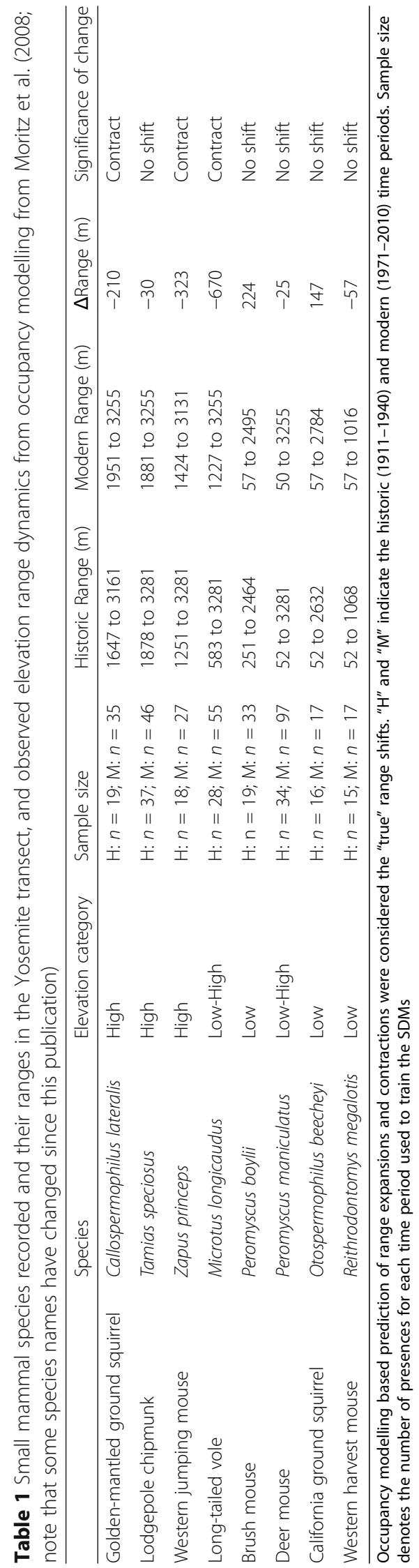


To train the SDMs we supplemented presence data from the trapping records with museum records that were not part of the original Grinnell Surveys or Grinnell Resurvey Project (Arctos, http://arctos.database.museum/home.cfm; and MaNIS, http://manisnet.org/; the MaNIS datasources can now be found in VertNet http:// www.vertnet.org/index.html). Augmenting the trapping records with the museum records was necessary to accommodate the number of predictors used in the SDMs. We only used presence sites recorded within the extent of the Yosemite transect (Fig. 1) collected during two time periods, 1900-1939 and 1970-2009. Museum specimens were subject to the same geo-referencing procedures and quality control as the trapping records to ensure locational precision. Mean coordinate uncertainty across all species and time periods was $412 \mathrm{~m}$, well within the error range necessary to generate accurate models [43].

We used the Maxent SDM (version 3.3.3 k) to model species' distributions through time. Maxent first uses "background" samples across the study region to estimate the probability of the environment across the landscape, then uses this to estimate the conditional probability of the environment given a presence occurs in that environment, then finally employs Bayes' theorem to invert this value to produce an estimate of habitat suitability [44]. Maxent is fairly robust to collinearity between variables owing to the use of regularization in fitting model coefficients [45]. For each time period, each species was modelled using three sets of predictors: climatic predictors alone, habitat alone, and climate with habitat (for additional description of the modelling workflow and discussion on the modelling framework see Additional file 1 S2). To correct for survey bias each species was modelled using all species' presences as target background points [46]. To reduce potential effects of spatial autocorrelation, presence points were spatially thinned so that sites occurred $>440 \mathrm{~m}$ of one another, a longer distance than the length of the diagonal of the pixel size of our environmental data. We used linear, quadratic, and interaction features and factor features when habitat was one of the predictors to ensure smoother responses. The regularization parameter, which determines the tightness of fit to the data, was tuned using Akaike's Information Criterion modified for small sample sizes $\left(\mathrm{AIC}_{\mathrm{c}}\right)$ [47]. Each species was modelled with each predictor set 10 times using random data splits ( $80 \%$ for training and $20 \%$ for testing) and once more using all of the species' data ("all-points" models). The all-points models were used to predict range shifts in the same and opposing time period. We calculated four measures of SDM performance: the Continuous Boyce Index (CBI), which measures the correlation of the model prediction with the actual probability of presence $[48,49]$; area under the receiver- operator curve (AUC) which indicates the probability that a presence site has a higher predicted value than a background site [44]; maximum $\mathrm{F}_{\mathrm{pb}}$, the mean of precision (proportion of presence predictions that are correct) and sensitivity (proportion of test presences correctly predicted) [50]; and the point-biserial correlation (COR), a measure of model calibration accuracy $[50,51]$.

We applied thresholds to the SDM predictions to delineate areas of predicted presence from absence. Thresholds were calculated using test presences and randomly located sites. We tested thresholds using the value that maximized sensitivity plus specificity (proportion of test presences and test absences correctly predicted; MSSS), minimized the difference between sensitivity and specificity (MDSS), and maximized $\mathrm{F}_{\mathrm{pb}}$ $\left(\max -\mathrm{F}_{\mathrm{pb}}\right)$ [50]. Only MSSS is guaranteed to have the same value if calculated using real absences or background sites [50-52]. Overall we found the MSSS threshold best matched observed range shifts, so for brevity we only present results using this threshold (the others are reported in supplementary material).

All-points models were projected to the same time period and to the opposing time period and thresholded using the MSSS threshold calculated from the k-fold models from the era from which the projection was made. Specifically, we examined whether the SDMs correctly predicted the trend observed in the elevation range (contraction or no shift-no species had an overall expansion), and the trend in the upper and lower elevation limits (contraction, expansion, or no shift). To do so, we calculated the elevation range using SDMs and compared these to "observed" ranges from OM [5]. For SDMs we determined that a range did not shift when the overall difference in the extent occupied by the species along the elevation profile did not exceed $100 \mathrm{~m}$ in elevation between historic and modern time. We repeated the same for both the upper and lower elevation range limits.

To assess whether species-environment relationships were constant over time, we compared the model coefficients from the all-points models trained using historic or modern variables. Maxent scales the coefficients by the variability in the data, which allows a direct assessment of the contribution of each variable in each time period [52, 53]. We also compared models using different predictor sets with $\mathrm{AIC}_{\mathrm{c}}$ (calculated during the model tuning process-see above), and identified the model with lowest $\mathrm{AIC}_{\mathrm{c}}$ from among the set of possible models. We considered models within 3 units of the lowest $\mathrm{AIC}_{\mathrm{c}}$ equivalent [53]. All analyses were performed in R Ver. 3.01 [54] using custom code and the "dismo" Ver. $0.9-3$ and "raster" Ver. 2.2-12 packages [55, 56] with Maxent 3.3.3 k [42]. 


\section{Results}

Comparison between observed and predicted range shifts Three species significantly contracted their overall elevation ranges (the Golden-mantled ground squirrel, longtailed vole, and Western jumping mouse) while the other five showed no shifts (Table 1). The same three species that contracted their ranges showed upwards contraction of their lower range limit by 300 to $600 \mathrm{~m}$, while downward contraction of upper range limit was minor with differences in elevation of only 30 to $60 \mathrm{~m}$. Species inhabiting mid-low elevations (below $1700 \mathrm{~m}$ ) and the deer mouse (which is ubiquitous) consistently showed no overall shifts.

The SDM trained with climate and habitat simultaneously correctly predicted observed contractions for the golden-mantled ground squirrel, long-tailed vole, and Western jumping mouse. The Brush mouse ( $P$. boylii) did not display a change in its overall range which was correctly predicted by the climate-only SDM (Table 2). Habitat-only models for the Western harvest mouse $(R$. megalotis) did not converge.

Upper/lower range limits were correctly predicted more frequently than overall range, especially when using climate or climate plus habitat as predictors. The SDMs trained using climate or climate plus habitat correctly predicted upper edge dynamics five of eight times and lower edge dynamics four of eight times. Habitat was only able to predict shifts of lower-elevation range limits in two cases, upward for the long-tailed vole and downwards for the brush mouse.

\section{Model coefficients}

Maximum and minimum temperature were the most important climate variables in climate-only models (Additional file $1 \mathrm{~S} 3$ ). Maximum temperature was the most important variable, as its coefficients stayed similar in direction and magnitude for 5 species between the historic and the modern era (Golden-mantled ground squirrel, Long-tailed vole, deer mouse, Western harvest mouse and lodgepole chipmunk). Minimum temperature was also consistently important across eras, for four species (Golden-mantled ground squirrel, California ground squirrel, Longtailed vole, and brush mouse). Temperature variables were also the most important variables for climate in combination with habitat models (Additional file 1 S3). In these models, the importance of climate variables overshadowed the importance of habitat, which only appeared as the most important variable in two instances - a historic negative relationship between mixed chaparral $(\mathrm{MCH})$ and the long-tailed vole, and a modern positive influence of montane hardwood conifer (MHC) for the California ground squirrel. Since the habitat-only models performed poorly we do not interpret their coefficients, but still present them in Additional file 1: S3.

\section{Model performance}

The best set of models was developed for the Goldenmantled ground squirrel, the lodgepole chipmunk and the Western jumping mouse, especially for climate-only and climate in combination with habitat sets of predictors. Models for deer mouse, a ubiquitous species, were very poor for all sets of predictors (Table 3). Most SDMs using only climate as a predictor had moderate AUC scores (Table 3; Additional file 1 S3). Within and across era performances were varied, but higher performance (i.e., higher AUC) was achieved for the modern era. Model performance achieved the highest performance scores when using climate and habitat as predictors simultaneously. Habitat alone generally performed no better and sometimes even worse than random given the average AUC scores around 0.5 (Table 3; Additional file 1 S3). In our case, models using only climate were less likely to be overfit, i.e., the difference between the cross-era CBI and within-era CBI was less for climate-only predictors than for models with habitat-only or climate with habitat (Additional file $1 \mathrm{~S} 3$ ).

\section{Discussion}

Overall we found weak influences of habitat and moderate influences of climate or climate plus habitat on species' elevation range shifts. Despite employing the most common predictors in other modelling studies [57], our SDMs correctly predicted the observed overall range shifts for only three species. These same variables were slightly better at predicting dynamics at specific range edges: trends in lower limits were correctly predicted five times and upper limits four times. Habitat alone rarely predicted overall range trend and the dynamics of specific range edges (one or two correct cases each). In contrast, predictions based on climate or climate plus habitat were more likely to be correct (three times for overall range trend and ten times for upper/lower limits combined). Nonetheless, we did find some evidence that lower-edge range limits are shaped by habitat: models that included habitat or climate plus habitat correctly predicted the lower edge trends for all six of the midlower elevation species. Despite these successes, model predictions often disagreed with observed range shifts. Five out of eight species showed no change at their upper elevation limits, a trend that no models predicted correctly. Overall, our results seem to suggest that 1) mammalian elevation range shifts are not tightly coupled to climate or habitat, but of those that are 2) climate is the more important driver, albeit with a subsidiary role for habitat in shaping lower-edge range shifts. This suggests that different mechanisms that may underlie the 


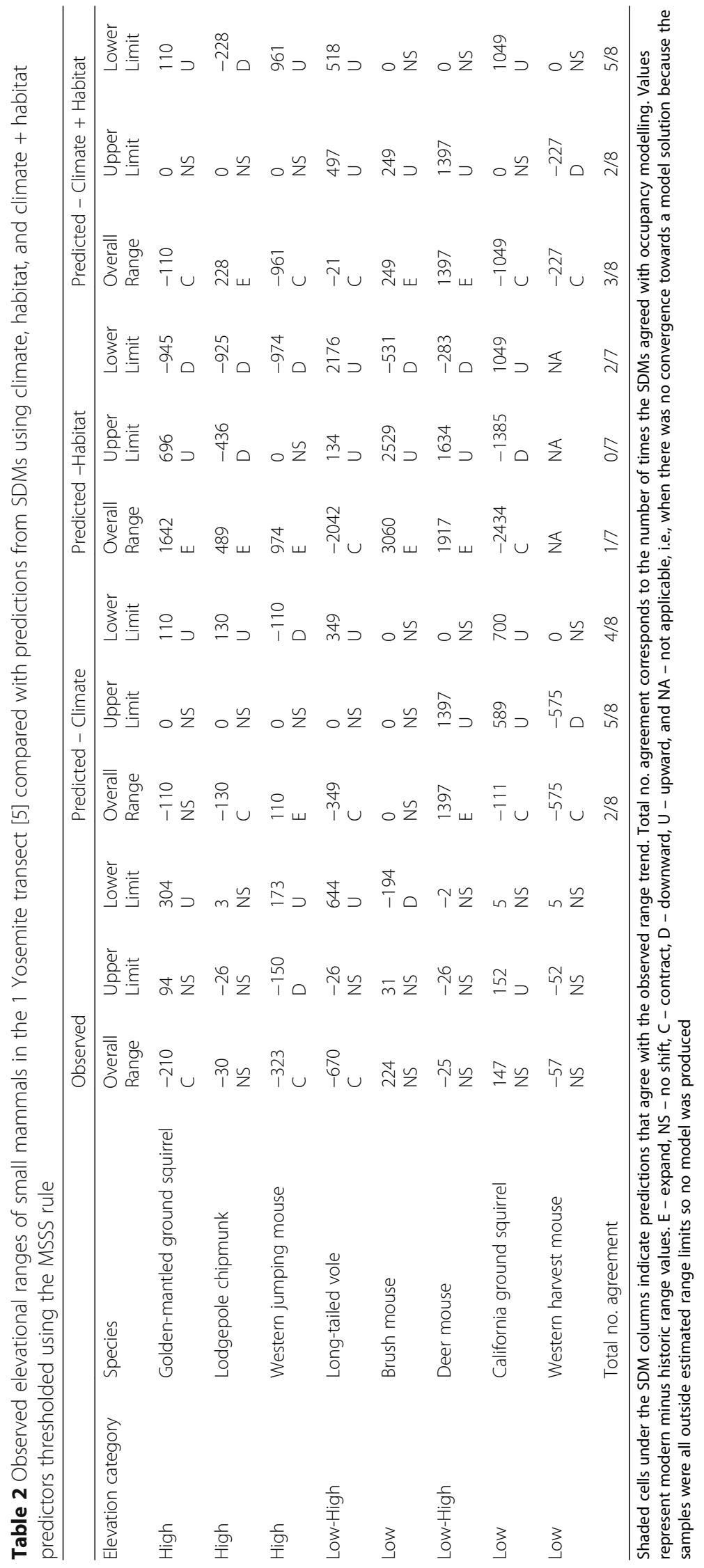


Table 3 SDM model selection and fit using difference in AICC ( $\triangle \mathrm{AICC})$ and AUC 1 metrics for each model

\begin{tabular}{|c|c|c|c|c|c|c|c|}
\hline & & $\triangle \mathrm{AlCC}$ & & & AUC & & \\
\hline Species & Era & Climate & Habitat & Climate + Habitat & Climate & Habitat & Climate + Habitat \\
\hline C. lateralis & historic & 8 & 36.4 & 0 & 0.72 & 0.52 & 0.70 \\
\hline C. lateralis & modern & 70.2 & 33.6 & 0 & 0.81 & 0.52 & 0.78 \\
\hline M. longicaudus & historic & 43.4 & 0.9 & 0 & 0.66 & 0.49 & 0.66 \\
\hline M. longicaudus & modern & 108 & 50.3 & 0 & 0.79 & 0.53 & 0.80 \\
\hline O. beecheyi & historic & 27.4 & 0 & 0.8 & 0.59 & 0.51 & 0.50 \\
\hline O. beecheyi & modern & 42.4 & 0 & 9.9 & 0.85 & 0.79 & 0.79 \\
\hline P. boylii & historic & 55.4 & 0 & 12.6 & 0.50 & 0.66 & 0.67 \\
\hline P. boylii & modern & 59.3 & 5.5 & 0 & 0.57 & 0.39 & 0.61 \\
\hline P. maniculatus & historic & 62.8 & 1.1 & 0 & 0.34 & 0.43 & 0.33 \\
\hline P. maniculatus & modern & 164.1 & 3.9 & 0 & 0.60 & 0.50 & 0.52 \\
\hline R. megalotis & historic & 22.7 & 8 & 0 & 0.69 & 0.59 & 0.70 \\
\hline R. megalotis & modern & 23.8 & 14.9 & 0 & 0.72 & 0.56 & 0.71 \\
\hline T. speciosus & historic & 64.1 & 18.3 & 0 & 0.78 & 0.56 & 0.77 \\
\hline T. speciosus & modern & 84.4 & 39.9 & 0 & 0.82 & 0.49 & 0.81 \\
\hline Z. princeps & historic & 25.9 & 5.4 & 0 & 0.75 & 0.58 & 0.72 \\
\hline Z. princeps & modern & 51.9 & 20.5 & 0 & 0.77 & 0.52 & 0.77 \\
\hline
\end{tabular}

Bold values in each row indicate non-separable models (with $\Delta$ AICc less than 2)

shifts in different parts of species' ranges [9, 58]. However, our results may also implicate conflicting influences of climate and habitat on range shifts. Disentangling these mechanisms requires further study at physiological and behavioural levels and accounting for biotic interactions $[59,60]$.

We found climate was generally more important than habitat in predicting species range shifts. Climate-based models were expected to perform better for high elevation species because there is potentially less amelioration of climate exposure from forests [13]; and because species at these elevations may be closer to their physiological limits and thus more affected by small changes in climate [30]. Our results show that species in high elevations experienced more range shifts, particularly contraction of their lower range limits, and that temperature was the most important predictor of these shifts. These species may be avoiding the warmer temperatures at their lower range limits. Thus, our results suggest that physiological limits of species play a key role in determining lower range limits of high elevation species [61]. Some of these physiological limitations could have been reduced by behavioural adaptations such as seeking shade under the vegetation canopy or rock crevices [62, 63]. Because such structures are widely available at these elevations, it suggests that these species may already be behaving in such way to ameliorate climate effects, but observational studies are needed to confirm such behavioural changes.
The high-elevation species in our study responded to a minor extent to habitat. It is possible that changes in the dominant preferred vegetation allowed these species to withstand unfavourable climates, since overstory canopies can create favourable ground-level microclimates [17]. The golden-mantled ground squirrel is one of the few high elevation species that is responding to the overall changes in its suitable habitats [13]. The Western jumping mouse is more likely responding to changes in water availability and associated habitat changes such as shrub or tree species encroachment over meadows [64]. This species prefers moist woodlands [65], and therefore likely affected by encroachment. This is corroborated by the change in the coefficient associated with Lodgepole pine from a non-zero value in the historic era to 0 in the modern era (Table S3.6). Our habitat data also shows a $50 \%$ decrease in meadow extent (from $62.28 \mathrm{~km}^{2}$ to $23.31 \mathrm{~km}^{2}$ ), and a persistence of montane riparian areas (ca. 6-7 $\mathrm{km}^{2}$ in both eras), and it agrees with the previously identified importance of meadows and riparian ecosystems for small mammals in the Sierras $[13,66]$. This could also explain the range contraction of the long-tailed vole, a meadow specialist $[67,68]$, which occurs from low- to high elevations. We found positive effects of Jeffrey pine, a high elevation pine, for this species.

The species at the other elevations showed no shifts in their ranges, and the SDMs also predicted no substantial change. However these were the elevations that experienced the most change in habitat and in climate, 
suggesting either that 1) other factors alter the speciesenvironment relationship or 2) there are opposing effects of climate and habitat that result in a net no shift in elevation range. Biotic interactions might obfuscate the relationship between species and the abiotic environment and physical habitat. For example, interspecific competition from other chipmunks has been implicated in driving range dynamics of the shadow chipmunk (Tamias senex) in the Yosemite transect [30]. While common during Grinnell's time, this species contracted its range to the extent that it is now so rare that we were unable to obtain sufficient presences for modelling. Similarly, evolutionary and behavioural flexibility might also "loosen" otherwise tight links between species and the abiotic environment [63]. Indeed, in the Yosemite transect the shadow chipmunk likely competes with the alpine chipmunk ( $T$. alpinus), which has not retracted its range as much. Over this time period the alpine chipmunk demonstrated greater dietary and morphological change compared to the shadow chipmunk [69], suggesting that behavioural and evolutionary flexibility could attenuate the influence of abiotic factors on ranges.

Climate and habitat have equal but opposing effects on species' range shifts. At low and mid- elevations we observed the greatest changes in both climate and habitat, but at the higher elevations climate had a more pronounced role in species range shifts than habitat while at the lower elevations habitat had a more consistent effect than climate. The lack of observed shift due to climate may arise because these low- to mid-elevation species already occupy a wide range of climate conditions, as they occur throughout a much wider elevation range, and are therefore adapted to variability in climate. An alternative explanation is that these species are lagging behind in their responses to changes in climate, as their favourable habitat is still present and potentially slowing down or neutralizing their responses to direct climate effects [13]. Finally, vegetation cover could be mediating the direct effects of climate. Our results seem to point in this direction as vegetation becomes an important predictor at mid-and lower elevations for California ground squirrel and the brush mouse. Disentangling such influences require more detailed studies that take all these aspects into consideration.

The lack of success of the SDMs may be due to procedural aspects of our study. For example, our choice of climate variables is a subset of the many that could have been calculated, and the classification scheme and crosswalks used to convert land cover into vegetation classes represent a balance between tractability and reality. Nonetheless, our predictors and methods for calculating them are fairly standard, so if indeed they have led to the mediocre performance of the SDMs, then other studies are equally liable in this regard and better attention should be paid to choice and definition of predictors [70]. Moreover, we used predictors at fairly high spatial resolution $(300 \mathrm{~m})$ which is likely to better capture the true relationship between species and the environment [71]. Species may not have been in equilibrium with their environment in either the historic or modern or both eras-a fundamental assumption made by correlative niche models [72]. Nonetheless, other work that includes the Yosemite transect and includes these same species suggest that SDMs (including Maxent) perform fairly well when projected across time [73]. Likewise, our fitting procedures are fairly standard and considered best practice for this algorithm [47]. And, we purposefully corrected for sampling bias using a targeted background approach [46].

\section{Conclusions}

Our results show that climate generally had a stronger effect on range shifts than habitat, especially at higher elevations, but neither set of factors alone or in conjunction reliably predicted observed range shifts. These results suggest that predictions of range shifts for upper and lower ranges across an entire elevation gradient based on either climate or habitat alone may be insufficient, as habitat and climate play varying roles at different elevations, associated with different processes underlying range shifts. Failure to predict observed range shifts may arise from biotic interactions, behaviour flexibility, or evolutionary adaptation, aspects which are only beginning to be incorporated into distribution modelling frameworks [74]. Information on the nature of the drivers of elevation range shifts determines management interventions that can be applied to help species adapt to climate change. For example, pre-emptive logging might have deleterious effects on species that respond more directly to vegetation than climate. Likewise, anthropogenic microclimates might offset responses of species whose ranges are shaped more strongly by climate [36]. Our study area has also experienced more recent high-impact stressors such as drought and fire, which could affect the predictions by long-term climate averages and vegetation alone. Understanding the cumulative impacts of climate and habitat shifts, along with disturbance on species elevation ranges is fundamental to avoid triggering a catastrophic shift in the biotic communities along this and other elevation gradients.

\section{Additional files}

Additional file 1: S1 Climate and vegetation variables. S2 Modelling framework. S3 SDM model evaluation metrics and variable coefficients (DOCX 133 kb) 


\section{Acknowledgements}

We are thankful to the Museum of Vertebrate Zoology at the University of California Berkeley and the Grinnell Resurvey project for the critical thinking and the mammal data - in particular Steve Beissinger and Jim Patton; to the Information Center for the Environment the University of California Davis for the historic (Wieslander Vegetation Type mapping project) and modern (CalVeg integration with Yosemite National Park vegetation map) land cover maps and crosswalk to Wildlife Habitat Relationship types.

\section{Funding}

Funding for this project was provided by the California Energy Commission under the PIER program (CEC 50-09-037).

\section{Availability of data and materials}

Mammal data can be found here (http://ecoreader.berkeley.edu/; Arctos, http:// arctos.database.museum/home.cfm; and MaNIS, http://manisnet.org/; VertNet http://www.vertnet.org/index.html), and previous project products here (http:// mvz.berkeley.edu/Grinnell/pubs.html). Climate data can be downloaded here: https://ca.water.usgs.gov/projects/reg_hydro/projects/dataset.html; Historic vegetation data can be downloaded here: http://vtm.berkeley.edu/\#/home; Modern vegetation data can be downloaded here: https://www.fs.usda.gov/ detail/r5/landmanagement/gis/?cid=STELPRDB5327836

\section{Authors' contributions}

MJS, ABS, JHT and CM provided the concept and designed the experiment; $\mathrm{JHT}$ and CM had major contributions in data collection; MJS and ABS analysed the data; MJS wrote the manuscript, $\mathrm{ABS}, \mathrm{JHT}$ and $\mathrm{CM}$ revised the manuscript critically for important intellectual content. All authors read and approved the final manuscript

\section{Ethics approval and consent to participate}

Our research does not involve human participants so this statement does not apply to our study.

\section{Consent for publication}

Not applicable

\section{Competing interests}

The authors declare that they have no competing interests.

\section{Publisher's Note}

Springer Nature remains neutral with regard to jurisdictional claims in published maps and institutional affiliations.

\section{Author details}

'Department of Innovation, Environmental and Energy Sciences, Utrecht University, Utrecht, Netherlands. ${ }^{2}$ Center for Conservation and Sustainable Development, Missouri Botanical Garden, PO Box 299, Saint Louis, MO 63166, USA. ${ }^{3}$ Information Center for the Environment, Department of Environmental Science and Policy, University of California, Davis, California, USA. ${ }^{4}$ Research School of Biology, Australian National University, Acton, ACT 0200, Australia.

Received: 1 June 2017 Accepted: 30 October 2017

Published online: 10 November 2017

\section{References}

1. La Sorte FA, Jetz W. Projected range contractions of montane biodiversity under global warming. Proc Roy Soc B. 2010;277:3401-10.

2. Ching-Chen I, Hill JK, Ohlemüller R, Roy DB, Thomas CD. Rapid range shifts of species associated with high levels of climate warming. Science. 2011;333:1024-6.

3. Parmesan C, Yohe G. A globally coherent fingerprint of climate change impacts across natural systems. Nature. 2003;421:37-42.

4. Walther GR, Post E, Convey P, Menzel A, Parmesan C, Beebee TJC, Fromentin JM, Hoegh-Guldberg O, Bairlein F. Ecological responses to recent climate change. Nature. 2002;416:389-95.

5. Moritz C, Patton JL, Conroy CJ, Parra JL, White GC, Beissinger SR. Impact of a century of climate change on small-mammal communities in Yosemite National Park. USA Science. 2008:322:261-4.

6. Lenoir J, Svenning J-C. Climate-related range shifts - a global multidimensional synthesis and new research directions. Ecography. 2015;38:15-28.
7. Oliver T, Hill JK, Thomas CD, Brereton T, Roy DB. Changes in habitat specificity of species at their climatic range boundaries. Ecol Lett. 2009;12: 1091-102.

8. Tingley MW, Monahan WB, Beissinger SR, Moritz C. Birds track their Grinnellian niche through a century of climate change. Proc Nat Acad Sci. 2009;17:19637-43.

9. Tingley MW, Koo MS, Moritz C, Rush AC, Beissinger SR. The push and pull of climate change causes heterogeneous shifts in avian elevational ranges. Glob Ch Biol. 2012;18:3279-90.

10. McCain CM, Colwell RK. Assessing the threat to montane biodiversity from discordant shifts in temperature and precipitation in a changing climate. Ecol Lett. 2011;14:1236-45.

11. Rapacciuolo G, Maher SP, Schneider AC, Hammond TT, Jabis MD, Walsh RE, Iknayan KJ, Walden GK, Oldfather MF, Ackerly DD, Beissinger SR. Beyond a warming fingerprint: individualistic biogeographic responses to heterogeneous climate change in California. Glob Ch Biol. 2014;20:2841-55.

12. Baselga A, Lobo JM, Svenning J-C, Araújo MB. Global patterns in the shape of species geographical ranges reveal range determinants. J Biogeogr. 2012;39:760-71.

13. Santos MJ, Thorne JH, Moritz C. Synchronicity in elevation range shifts among small mammal and vegetation over the last century is stronger for omnivores. Ecography. 2014;37:1-13.

14. Sunday JM, Bates AE, Dulvy NK. Thermal tolerance and the global redistribution of animals. Nature Clim Ch. 2012;2:686-90.

15. Sheldon KS, Yang S, Tewksbury JJ. Climate change and community disassembly: impacts of warming on tropical and temperate montane community structure. Ecol Lett. 2014;14:1191-200.

16. Radeloff VC, Williams JW, Bateman BL, Burke KD, Carter SK, Childress ES, Cromwell K, Gratton C, Hasley AO, Kraemer BM, Latzka AW, Marin-Spiotta E, Meine BM, Munoz SE, Neeson TM, Szymanski LM, Usinowicz J. The rise of novelty in ecosystems. Ecol Appl. 2015;25:2051-68.

17. De Frenne P, Rodríguez-Sánchez F, Coomes DA, Baeten L, Verstraeten G, Vellend M, Bernhardt-Römermann M, Brown CD, Brunet J, Cornelis J, Decocq GM, Dierscke H, Eriksson O, Gilliam FS, Hédl R, Heinken T, et al. Microclimate moderates plant responses to macroclimate warming. Proc Nat Acad Sci. 2013:110:18561-5.

18. Dobrowski SZ, Thorne JH, Greenberg JA, Safford HD, Mynsberge AR, Crimmins SM, Swanson AK. Modeling plant distributions over 75 years of measured climate change in California, USA: relating temporal transferability to species traits. Ecol Monogr. 2011;81:241-57.

19. Inouye DW. Effects of climate change on phenology, frost damage, and floral abundance of montane wildflowers. Ecology. 2008;89:353-62.

20. Post ES, Pedersen C, Wilmers CC, Forchhammer MC. Phenological sequences reveal aggregate life history response to climatic warming. Ecology. 2008;89:363-70.

21. Hof C, Levinsky I, Araújo MB, Rahbek C. Rethinking species' ability to cope with rapid climate change. Glob Ch Biol. 2011;17:2987-90.

22. Kearney M, Porter W. Mechanistic niche modelling: combining physiological and spatial data to predict species' ranges. Ecol Lett. 2009;12:334-50.

23. Betts MG, Nocera JJ, Hadley AS. Settlement in novel habitats induced by social information may disrupt community structure. Condor. 2010;112:265-73.

24. Ralston J, DeLuca WV, Feldman RE, King DI. Population trends influence species ability to track climate change. Glob Ch Biol 2016. DOl: https://doi. org/10.1111/gcb.13478

25. Yu F, Groen TA, Wang T, Skidmore AK, Huang J, Ma K. Climatic niche breadth can explain variation in geographical range size of alpine and subalpine plants. Int J Geog Inf Sci. 2017;31:1.

26. McCain CM. Vertebrate range sizes indicate that mountains may be 'higher' in the tropics. Ecol Lett. 2009;12:550-60.

27. Humphries MM, Umbanhowar J, McCann KS. Bioenergetic prediction of climate change impacts on northern mammals. Int Comp Biol. 2004;44:152-62.

28. Barton BT, Schimtz OJ. Experimental warming transforms multiple predator effects in a grassland food web. Ecol Lett. 2009;12:1317-25.

29. Holmes CW. A note on the protection provided by the hair coat or fleece of the animal against the thermal effects of simulated rain. Anim Prod. 1981:32:225-6.

30. Rubidge EM, Monahan WB, Parra JL, Cameron SE, Brashares JS. The role of climate, habitat, and species co-occurrence as drivers of change in small mammal distributions over the past century. Glob Ch Biol. 2011;17:696-708.

31. Morelli TL, Smith AB, Kastely CR, Mastroserio I, Moritz C, Beissinger SR. Anthropogenic refugia ameliorate the severe climate-related decline of 
a montane mammal along its trailing edge. Proc Roy Soc Lond B. 2012; 279:4279-86.

32. Santos MJ, Watts T, Pincetl S. The push and pull of Land Use Policy: Reconstructing 150 Years of Development and Conservation Land Acquisition. PlosONE. 2014; DOI: 10.1371/journal.pone.0103489

33. Flint LE, Flint AL. Downscaling future climate scenarios to fine scales for hydrologic and ecological modelling and analysis. Ecol Proc. 2012;1:1-15.

34. Flint $\mathrm{LE}$, Flint $\mathrm{AL}$, Thorne JH, Boynton RM. Fine-scale hydrological modeling for regional landscape applications: model development and performance. Ecol Proc. 2013;2:25.

35. Daly C, Gibson WP, Taylor GH, Johnson GL, Pasteris P. A knowledge-based approach to the statistical mapping of climate. Clim Res. 2002;22:99-113.

36. Thorne JH, Boynton RM, Flint LE, Flint AL. The magnitude and spatial patterns of historical and future hydrologic change in California's watersheds. Ecosphere. 2015;6(2):24. http://dx.doi.org/10.1890/ES14-00300.1.

37. Thorne JH, Morgan BJ, Kennedy JA. Vegetation change over 60 years in the central sierra Nevada. Madrono. 2008;55:223-37.

38. Thorne JH, Le NG. California's historic legacy for landscape change, the Wieslander vegetation type maps. Madrono. 2016:63:293-328.

39. van Proosdij ASJ, Sosef MSM, Wieringa JJ, Raes N. Minimum required number of specimen records to develop accurate species distribution models. Ecography. 2015;39:542-52.

40. Grinnell J, Storer T. Animal life in the Yosemite - University of California Press 1924.

41. MacKenzie DI, Nichols JD. Occupancy as a surrogate for abundance estimation. An Biodiv Conserv. 2004;27:461-7.

42. MacKenzie DI, Nichols JD, Royle JA, Pollock KH, Bailey LL, Hines JE. Occupancy estimation and modeling: inferring patterns and dynamics of species occurrence. Amsterdam: Elsevier; 2006. p. 324.

43. Graham CH, Elith J, Hijmans RJ, Guisan A, Peterson AT, Loiselle BA, the NCEAS Predicting Species Distributions Working Group. The influence of spatial errors in species occurrence data used in distribution models. J Appl Ecol. 2008;45:239-47.

44. Phillips SJ, Anderson RP, Schapire RE. Maximum entropy modelling of species geographic distributions. Ecol Model. 2006;190:231-59.

45. Elith J, Phillips SJ, Hastie T, Dudík M, Chee YE, Yates CJ. A statistical explanation of MaxEnt for ecologists. Divers Distrib. 2011;17:43-57.

46. Phillips SJ, Dudík M, Elith J, Graham CH, Lehmann A, Leathwick J, Ferrier S. Sample selection bias and presence-only distribution models: implications for background and pseudo-absence data. Ecol Appl. 2009;19:181-97.

47. Warren DL, Siefert SN. Ecological niche modelling in Maxent: the importance of model complexity and the performance of model selection criteria. Ecol Appl. 2011;21:335-42.

48. Boyce MS, Vernier PR, Nielsen SE, Schmiegelow FKA. Evaluating resource selection functions. Ecol Model. 2002;157:281-300.

49. Hirzel AH, Le Lay G, Helfer V, Randin C, Guisan A. Evaluating the ability of habitat suitability models to predict species presences. Ecol Model. 2006;199:142-52.

50. Li W, Guo Q. How to assess the prediction accuracy of species presenceabsence models without absence data? Ecography. 2013;36:788-99.

51. Liu C, White M, Newell G. Selecting thresholds for the prediction of species occurrence with presence-only data. J Biogeogr. 2013;40:778-89.

52. Elith J, Graham CH, Anderson RP, Dudik M, Ferrier S, Guisan A, Hijmans RJ, Huettmann F, Leathwick JR, Lehmann A, Li J, Lohmann LG, Loiselle BA, Manion G, Moritz C, Nakamura M, Nakazawa Y, Overton J. McC, Peterson AT, Phillips SJ, Richardson K, Scachetti-Pereira R, Schapire RE, Soberón J, Williams S, Wisz MS, Zimmermann NE. Novel methods improve prediction of species' distributions from occurrence data. Ecography. 2006;29:129-51.

53. Burnham KP, Anderson DR. Model selection and multimodel inference: a practical information-theoretic approach. 2nd ed. New York: Springer; 2002.

54. R Core Development Team. R: a statistical application for computing. (http://www.r-project.org/) 2013.

55. Hijmans RJ, Phillips S, Leathwick J, Elith J. "dismo" package for R. (http://cran. r-project.org/web/packages/dismo/index.html) 2013.

56. Hijmans RJ, van Etten J, Mattiuzzi M, Sumner M, Greenberg JA, Lamigueiro OP, Bevan A, Racine EB, Shortridge A. "raster" package for R. (http://cran.r-project. org/web/packages/raster/index.html) 2014.

57. Bradie J, Leung B. A quantitative synthesis of the importance of variables used in MaxEnt species distribution models. J Biogeogr. 2017;44:1344-61.

58. Rowe KC, Rowe KMC, Tingley MW, Koo MS, Patton JL, Conroy CJ, Perrine JD, Beissinger SR, Moritz C. Spatially heterogeneous impact of climate change on small mammals of montane California. Proc Roy Soc Lond B. 2014;282: 20141857.

59. Meineri E, Skarpaas O, Vandvik V. Modeling alpine plant distributions at the landscape scale: do biotic interactions matter? Ecol Model. 2012;231:1-10.

60. Meineri E, Devillem AS, Gremillet D, Gauthier-Clerc M, Bechet A. Combining correlative and mechanistic habitat suitability models to improve ecological compensation. Biol Rev. 2015;90:314-29.

61. Wilson RJ, Gutierrez D, Gutierrez J, Martinez D, Agudo R, Monserrat VJ. Changes to the elevational limits and extent of species ranges associated with climate change. Ecol Lett. 2005;8:1138-46.

62. Stewart JA, Perrine JD, Nichols LB, Millar Cl, Thorne JH, Goerhing KE, Massing $\mathrm{CP}$, Wright $\mathrm{DH}$. Revisiting the past to foretell the future: summer temperature and habitat area predict pika extirpations in California. J Biogeogr. 2015;42:880-90.

63. Beever EA, Hall LE, Varner J, Loosen AE, Dunham JB, Gahl MK, Smith FA, Lawler J. Behavioral flexibility as a mechanism for coping with climate change. Front Ecol Environ. 2017;15:299-308.

64. Millar Cl, Westfall RD, Delany DL. Response of high-elevation limber pine (Pinus flexilis) to multiyear droughts and 20th-century warming, sierra Nevada, California, USA. Can J For Res. 2007;37:2508-20.

65. Hart EB, Belk MC, Jordan E, Gonzalez MW. Zapus princeps. Mammal Species. 2004;749:1-7.

66. Kelt DA, van Vuren $\mathrm{DH}$, Johnson ML, Wilson JA, Innes RJ, Jesmer BR, Ingram KP, Smith JR, Bigelow SW, Burnett RD, Stine PA. Small mammals exhibit limited spatiotemporal structure in sierra Nevada forests. J Mamm. 2013;94: 1197-213.

67. Jenkins SH, Eshelman BD. Spermophilus beldingi. Mam Sp. 1984;221:1-8

68. Smolen M, Keller BL. Microtus longicaudus. Mam Sp. 1987;271:1-7.

69. Walsh RE, Assis APA, Patton JL, Marroig G, Dawson TE, Lacey EA. Morphological and dietary responses of chipmunks to a century of climate change. Glob Ch Biol. 2016;22:3233-52.

70. Petitpierre B, Broennimann O, Kueffer C, Daehler C, Guisan A. Selecting predictors to maximize the transferability of species distribution models: lessons from cross-continental plant invasions. Glob Ecol Biogeog. 2017;26:275-87.

71. Mclnery GJ, Purvis DW. Fine-scale environmental variation in species distribution modelling: regression dilution, latent variables and neighbourly advice. Met Ecol Evol. 2011;2:248-57.

72. Wiens JA, Stralberg D, Jongsomjit D, Howell CA, Snyder MA. Niches, models, and climate change: assessing the assumptions and uncertainties. Proc Nat Acad Sci USA. 2009;106:19729-36.

73. Smith AB, Santos MJ, Koo M, Rowe KMC, Rowe KC, Patton JL, Perrine J, Beissinger $S$, Moritz C. Evaluation of species distribution models by resampling of sites surveyed a century ago by Joseph Grinnell. Ecography. 2013;36:1017-31.

74. Cabral JS, Valente L, Hartig F. Mechanistic simulation models in macroecology and biogeography: state-of-the-art and prospects. Ecography. 2017;40:267-80.

\section{Submit your next manuscript to BioMed Central and we will help you at every step:}

- We accept pre-submission inquiries

- Our selector tool helps you to find the most relevant journal

- We provide round the clock customer support

- Convenient online submission

- Thorough peer review

- Inclusion in PubMed and all major indexing services

- Maximum visibility for your research

Submit your manuscript at www.biomedcentral.com/submit
) Biomed Central 